\title{
The rabbit as a model for neurourologic studies of the lower genitourinary tract *
}

\author{
Christian G. Stief**, Francois Benard, Ruud J. L.H. Bosch, Sherif R. Aboseif, and Emil A. Tanagho \\ Department of Urology, University of California, School of Medicine, San Francisco, CA 94143, USA
}

Summary. We evaluated the rabbit as an animal model for the elucidation of the neurophysiology of erection, ejaculation, and bladder function. In 24 rabbits, stimulation of the hypogastric nerves resulted in penile tumescence and contraction of the seminal vesicles and vasa deferentia. Stimulation of the sympathetic trunks induced contraction of the penis, seminal vesicles, and vasa deferentia. Cavernous nerve stimulation induced penile erection with a mean intracavernous pressure of $113 \mathrm{~cm}$ $\mathrm{H}_{2} \mathrm{O}$. Pelvic nerve stimulation elicited bladder contraction, but the intraluminal pressure was low (mean, $9.6 \mathrm{~cm}$ $\mathrm{H}_{2} \mathrm{O}$ ) in comparison with that in other species. Our results indicate that the rabbit may be an appropriate, relatively inexpensive, and readily available model for the study of ejaculatory and erectile systems in man. However, because of anatomic variations, the rabbit bladder appears to be unsuitable for comparative studies in humans.

Eckhard [8] first described the application of modern electrophysiologic methods to the penile erectile system of dogs in his classic article of 1863 . After dissection, somatic and autonomic nerves were stimulated and the erectile response was recorded. The same author reported similar experiments in the rabbit 13 years later [9]. Since then, similar neurourologic experiments have been described in dogs $[2,7,11,12,17]$, monkeys [14], cats [6, $10,15,16]$, rabbits [18-20], and rats $[3,4,21]$.

Animal studies are necessary for an understanding of the neurophysiology of the lower genitourinary tract and for assessment of the effect of different types of treatment. In recent years, ethical and financial considerations have reduced the number of such studies. The rabbit is similar to the rat in cost and availability, but its greater

\footnotetext{
* This work was supported by grants from the Deutsche Forschungsgemeinschaft (DFG Sti 96/1 und Sti 96/2-1).

** To whom correspondence should be addressed at: Klinik für Urologie, Medizinische Hochschule, Konstanty-Gutschow-Strasse 8, W-3000 Hannover 1, Federal Republic of Germany
}

size offers more ease in dissection and in the recording of biologic effects. We undertook this study to evaluate the rabbit as a possible animal model for the study of the neurophysiology of the lower genitourinary tract.

\section{Materials and methods}

A total of 24 white New Zealand rabbits weighing $2.8-3.5 \mathrm{~kg}$ were used. After they had been given adequate anesthesia with i.p. pentobarbital $(40 \mathrm{mg} / \mathrm{kg})$, the rabbits were placed in a supine position on a heating pad. Anesthesia was maintained with $6.5 \mathrm{mg}$ i.v. bolus injections of pentobarbital as needed, and the rabbits received warm saline i.v. $\left(2 \mathrm{ml} / \mathrm{kg}^{-1} / \mathrm{h}^{-1}\right)$. The animals breathed spontaneously. Systemic blood pressure was monitored through a 22-gauge angiocatheter in the left femoral artery.

The abdomen was opened by a midline incision. The rectum was double-ligated and severed, and the mesentery of the proximal rectum and distal colon was dissected up to the inferior mesenteric artery. The distal colon was then placed in the upper abdomen. Hypogastric nerves, sympathetic trunks at the level of $\mathrm{L}_{6}-\mathrm{S}_{1}$, pelvic nerves (distal to the branching of the cavernous nerve), and cavernous nerves were dissected. Custom-made electrodes (coated platinum-iridium wires and medical quality silastic) were placed around these structures (Fig. 1). Stimulation parameters were: $1-4 \mathrm{~V}, 20 \mathrm{~Hz}$ frequency, $1 \mathrm{~ms}$ pulse width, and 30-s duration. The abdomen was filled with paraffin oil at $37^{\circ} \mathrm{C}$. Additional heat was provided with a heating lamp. Three sets of experiments were done.

\section{Neurophysiology of the ejaculatory system}

In eight rabbits, a 21 -gauge needle was inserted into a seminal vesicle for pressure monitoring. A 25-gauge needle was placed into one of the vasa deferentia and then connected to a $T$-tube for continuous perfusion of warm saline (Harvard Apparatus; perfusion rate $0.068 \mathrm{ml} / \mathrm{min}$ ) and simultaneous pressure recording (Fig. 2). Bilateral sympathetic trunks, hypogastric nerves, and cavernous nerves were independently stimulated and the response of the vas deferens and seminal vesicle was recorded. If the seminal vesicle contracted, the expulsed volume was replaced with warm saline. The first ejaculate was evaluated for the presence of sperm by optic microscopy (X 200). Simultaneous stimulations of the cavernous nerves and hypogastric nerves were also done.

\section{Neurophysiology of the erectile system}

The cavernous bodies were freed from the penile skin in eight rabbits. A 21 -gauge needle was inserted into one cavernous body for pressure re- 


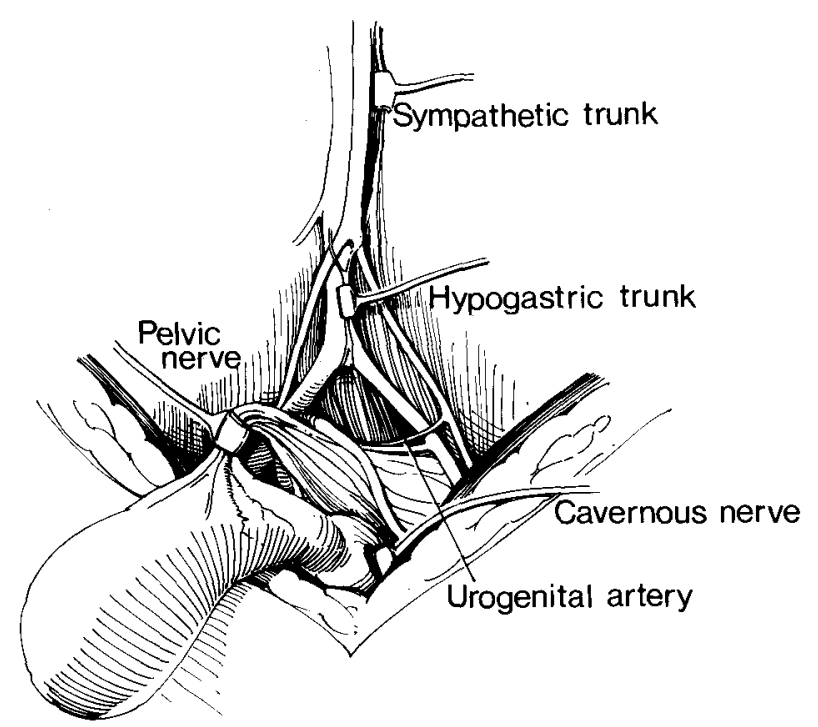

Fig. 1. Custom-made electrodes are placed around both sympathetic trunks, the hypogastric nerves, the left pelvic nerve, and the left cavernous nerve

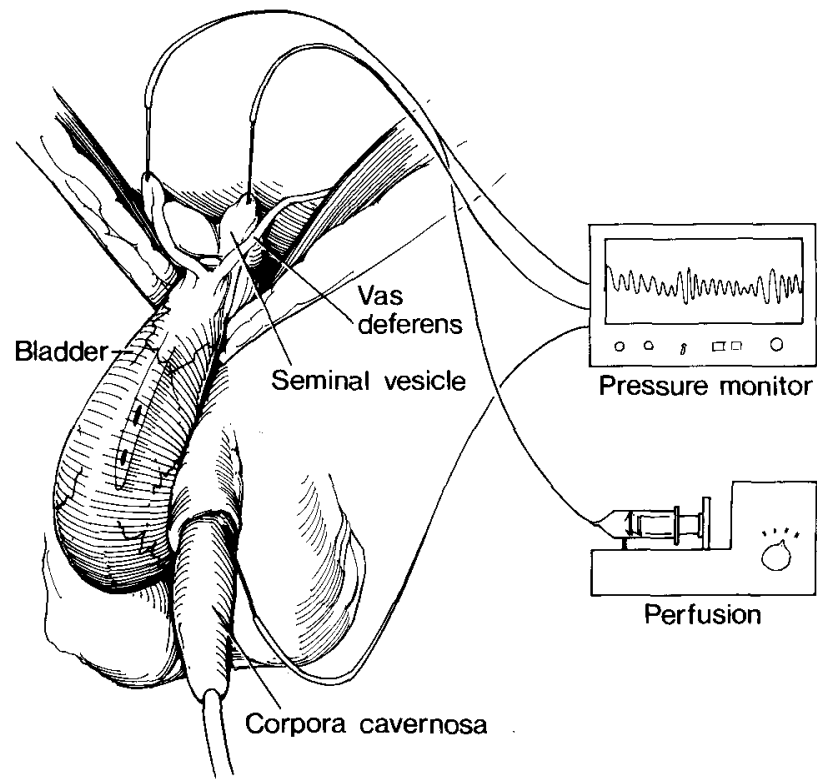

Fig. 2. Intraluminal pressure was recorded from the left seminal vesicle, the right vas deferens, the bladder, and the cavernous bodies. The vas deferens was also perfused with warm saline $(0.068 \mathrm{ml} / \mathrm{min})$

cording (Fig. 2). The tubing was filled with heparinized saline to prevent clotting. Bilateral sympathetic trunk, hypogastric nerve, and unilateral cavernous nerve stimulations were done independently. The hypogastric nerves and sympathetic trunks were also stimulated during erection induced by cavernous nerve stimulation.

\section{Neurophysiology of the lower urinary tract}

In eight rabbits, a 3-F catheter was placed transurethrally into the bladder (Fig. 2). The catheter was connected to a fluid-filled line via a threeway stopcock, which allowed for bladder filling and emptying. The bladder was emptied (volume $15-140 \mathrm{ml}$ ) and bladder capacity was determined cystometrically. All stimulations were done after the bladder had been filled to three-quarters of its capacity with warm saline. Bilateral sympathetic trunk, hypogastric nerve, and cavernous nerve stimulation were done independently. Stimulations of one or both pelvic nerves were done either alone or simultaneously with stimulation of the hypogastric nerves or sympathetic trunks.

All catheters and fluid-filled lines were connected to a Statham (model $23 \mathrm{BC}$ ) transducer for pressure recording (Grass Polygraph model 7). All stimulations or stimulation combinations were repeated three times in each rabbit and the results are expressed as the mean of these findings. Statistical analysis was done using Student's $t$-test.

\section{Results}

\section{Neurophysiology of the ejaculatory system}

Baseline pressure within the seminal vesicles was 2-7 (mean 4) $\mathrm{cm} \mathrm{H}_{2} \mathrm{O}$. Stimulation of the hypogastric nerves induced contraction of the seminal vesicles in all rabbits, with an intraluminal pressure of $23-37$ (mean 28) $\mathrm{cm}$ $\mathrm{H}_{2} \mathrm{O}$ (Fig. 3 A). This contraction was accompanied by emission of a white, sperm-containing fluid. The same response was observed after both sympathetic combined hypogastric and sympathetic stimulation. Stimulation of the cavernous nerve alone did not influence the intraluminal pressure. However, when the cavernous nerve was stimulated before and/or during seminal vesicle contraction, the intraluminal peak pressure was reduced by a mean of $7 \mathrm{~cm} \mathrm{H}_{2} \mathrm{O}$ (Fig. 3 B).

During perfusion, the intraluminal pressure of the vas deferens was 14-23 (mean 20) $\mathrm{cm} \mathrm{H}_{2} \mathrm{O}$. Spontaneous contractions with an interval of $15-45 \mathrm{~s}$ between each wave and a mean pressure increase of $8 \mathrm{~cm} \mathrm{H} \mathrm{H}_{2} \mathrm{O}$ were recorded. Stimulation of the hypogastric nerves induced an intraluminal pressure increase of $8-11$ (mean 9.3 ) $\mathrm{cm}$ $\mathrm{H}_{2} \mathrm{O}$, and stimulation of the sympathetic trunks induced a mean pressure increase of $8 \mathrm{~cm} \mathrm{H}_{2} \mathrm{O}$. Combined stimu-

A
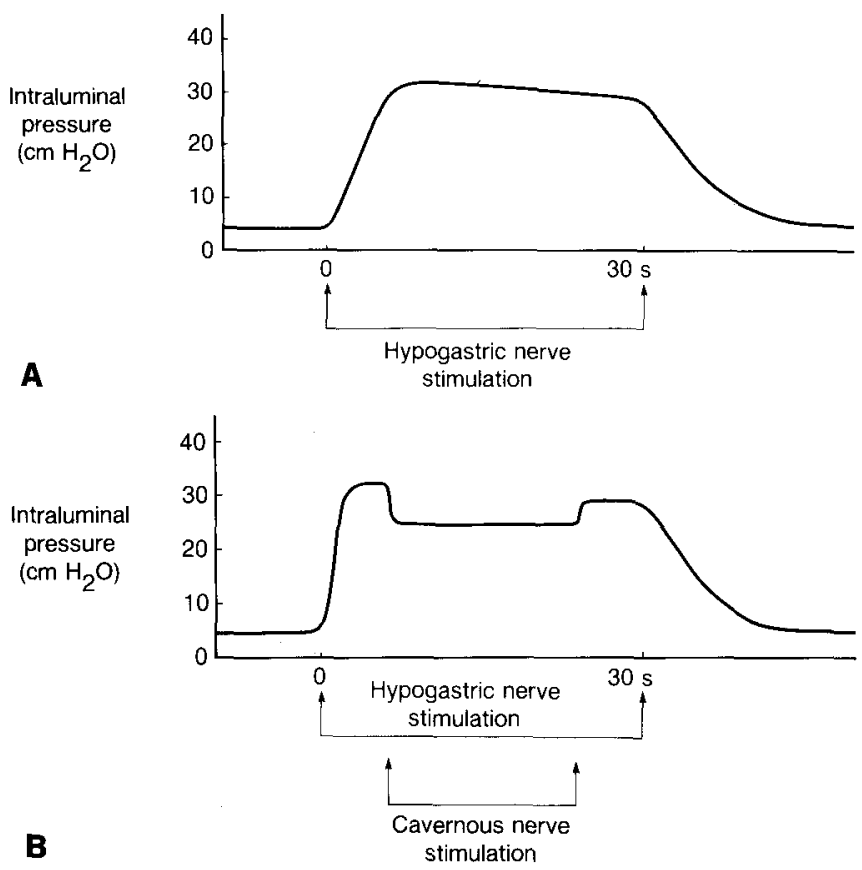

Fig. 3. A Stimulation of the hypogastric nerves or sympathetic trunks induced contraction of seminal vesicles. B Concomitant cavernous nerve stimulation reduced the pressure elevation provoked by hypogastric nerve stimulation, but this reduction was reversible on termination of cavernous stimulation 
lation of the hypogastric nerves and sympathetic trunks induced a mean pressure increase of $8.5 \mathrm{~cm} \mathrm{H}_{2} \mathrm{O}$.

\section{Neurophysiology of the erectile system}

The baseline intracavernous pressure was 13-24 (mean 19) $\mathrm{cm} \mathrm{H}_{2} \mathrm{O}$. Stimulation of the sympathetic trunks induced visible penile shrinkage and an intracavernous pressure increase of 4-11 (mean 6) $\mathrm{cm} \mathrm{H}_{2} \mathrm{O}$. Unilateral stimulation of the hypogastric nerves (duration $60 \mathrm{~s}$ ) resulted in penile protrusion and moderate tumescence without intracavernous pressure changes. Stimulation of the cavernous nerve induced full penile erection, with an intracavernous pressure of $105-125$ (mean 113) $\mathrm{cm} \mathrm{H}_{2} \mathrm{O}$ (Fig. 4). The erectile response to cavernous nerve stimulation was not changed by either previous or concomitant hypogastric stimulation. Stimulation of the sympathetic trunks during full erection induced by cavernous nerve stimulation abolished the erection in five of eight rabbits. In the remaining three animals, it did not reduce the intracavernous pressure during cavernous nerve stimulation.

\section{Neurophysiology of the lower urinary tract}

After the bladder had been slowly filled to three-quarters of its capacity, the intravesical pressure was 3-7 (mean 4) $\mathrm{cm} \mathrm{H}_{2} \mathrm{O}$. Stimulation of the hypogastric nerves, sympathetic trunks, or cavernous nerves had no effect. Unilateral stimulation of the pelvic nerve induced an intravesical pressure increase of 7-11 (mean 9.6) $\mathrm{cm} \mathrm{H}_{2} \mathrm{O}$ (Fig. 5). Bilateral stimulation of the pelvic nerves resulted in an intravesical pressure increase of $11-15$ (mean 13.2) $\mathrm{cm} \mathrm{H}_{2} \mathrm{O}$. The difference between the increases induced by unilateral and bilateral pelvic nerve stimulation was statistically significant $(P<0.05)$. Stimulation of the sympathetic trunks before and/or during unilateral or bilateral pelvic nerve stimulation did not influence the intravesical pressure in comparison with pelvic nerve stimulation alone.

\section{Discussion}

To date, the monkey has been the preferred animal model for the study of the neurophysiology of ejaculation because of the similarities between its ejaculatory system and that of man [1].

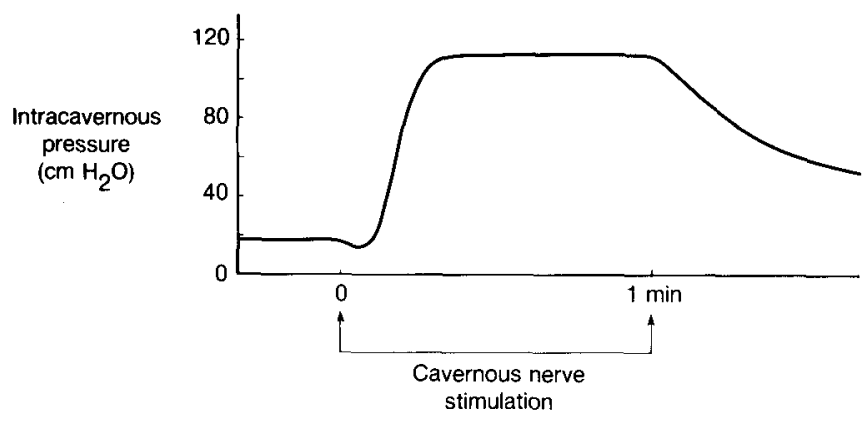

Fig. 4. Cavernous nerve stimulation induced a rise in intracavernous pressure to about $90 \%$ of the systemic blood pressure
Electrical stimulation of the hypogastric nerves or sympathetic trunks in the present study resulted in contraction of the seminal vesicles and vasa deferentia, followed by the emission of semen. These observations in the rabbit are in accord with the findings of Brindley [1], who described ejaculation provoked by sympathetic trunk stimulation in monkeys. The reason for the decrease in intraluminal pressure induced by cavernous nerve stimulation (see Fig. 3 B) is speculative. It may have been due to an enlargement of the opening of the seminal vesicle into the prostatic urethra during the erectile response or to a reflexogenic inhibition of the contraction via an afferent nerve pathway.

As in other species $[13,21]$ cavernous nerve stimulation induced full penile erection in rabbits, with an intracavernous pressure of about $90 \%$ of the systemic blood pressure. Intracavernous pressure recording in the rat is difficult, and measurements are less reliable than those obtained in the rabbit (penile length $>2 \mathrm{~cm}$ in the erect state).

The rabbit presents several advantages over the dog, which is an animal model commonly used for the study of erection. As in man, the rabbit corpora communicate, whereas the dog has two separate corpora, with venous drainage occurring via the cavernous veins only $[2,7]$. The induction of erection in the dog results in penile rigidity with no visible tumescence. In contrast, penile erection in the rabbit is similar to that in man, with visible tumescence and rigidity. The response of the corpora cavernosa to basic pharmacologic substances (epinephrine, norepinephrine, and acethylcholine) has been studied in detail and correlates well with studies done in humans [18].

Stimulation of the hypogastric nerves induced penile protrusion with a moderate increase in tumescence. Eckhard [9] as well as Sjöstrand and Klinge [18] reported full penile tumescence after hypogastric stimulation. This different erectile response may have been due to the voltage applied. We used 1-4 V, whereas the above-mentioned investigators applied supramaximal $(15-25 \mathrm{~V})$ voltage, which is less physiologic.

As described in dogs [5, 14], stimulation of the sympathetic trunks led to penile contraction and abolished the erection induced by cavernous nerve stimulation in more than half of the rabbits in the present study. Sjöstrand and Klinge [18] also described a decrease in penile volume in the rabbit after sympathetic trunk stim-

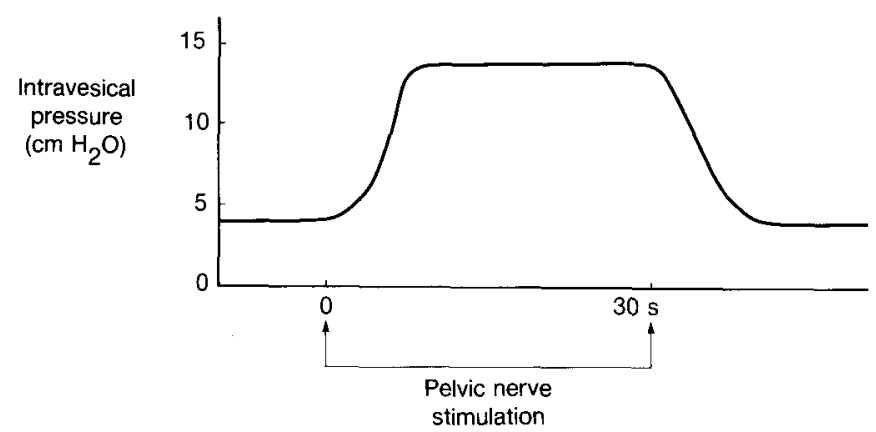

Fig. 5. Pelvic nerve stimulation induced bladder contraction with a mean intravesical pressure increase of $9.6 \mathrm{~cm} \mathrm{H}_{2} \mathrm{O}$ 
ulation. This is an important finding, considering the well-known effect of stress on erection and its possible role in psychogenic impotence.

The rabbit does not mark his territory with urine and can store great amounts. This behavior may be responsible for the thin bladder wall and the relatively low intravesical pressure that occurs during bladder contractions induced by pelvic nerve stimulation. In the dog, sympathetic stimulation before and during pelvic nerve stimulation increases the intravesical pressure over the level reached by pelvic nerve stimulation alone (unpublished results). In contrast, this combined stimulation does not change the intravesical pressure response in the rabbit.

Our results indicate that the rabbit may be a useful animal model for the study of the physiology and pathophysiology of ejaculatory and erectile systems in man. It also has the advantages of ready availability and low cost. However, important differences between species must be considered, e.g., hypogastric stimulation induces penile tumescence in rabbits but not in dogs or monkeys. Due to its large bladder capacity and low pressure response to pelvic nerve stimulation, the rabbit does not seem to be a suitable model for the study of human bladder (dys)function.

Acknowledgement. Dr. Stief is the recipient of a grant from the Deutsche Forschungsgemeinschaft.

\section{References}

1. Brindley G (1981) Electroejaculation: its technique, neurological implication and use. J Neurol Neurosurg Psychiatry 44:9

2. Carati CJ, Creed KE, Keogh EJ (1987) Autonomic control of penile erection in the dog. J Physiol 384:525

3. Clark JT, Smith EP, Davidson JM (1985) Evidence for the modulation of sexual behavior by alpha-adrenoreceptors in male rats. Neuroendocrinology 41:36

4. Dail WG, Evan AP (1974) Experimental evidence indicating that the penis of the rat is innervated by short adrenergic neurons. Am J Anat 141:203
5. Diederichs W, Stief CG, Benard F, Bosch RJLH, Lue TF, Tanagho EA (1988) Sympathetic effect on erection in dogs and monkeys: J Urol 139:253A

6. Domer FR, Wessler G, Brown RL, Charles HC (1978) Involvement of the sympathetic nervous system in the urinary bladder internal sphincter and in penile erection in the anesthetized cat. Invest Urol $15: 404$

7. Dorr LD, Brody MJ (1967) Hemodynamic mechanisms of erection in the canine penis. Am J Physiol 213:1526

8. Eckhard C (1863) Untersuchungen über die Erektion des Hundes. Beitr Anat Physiol 3:123

9. Eckhard C (1876) Über den Verlauf der nn. erigentes innerhalb des Rückenmarkes und Gehirns. Beitr Anat Physiol 3:69

10. Groat WC de, Ryall RW (1967) An excitatory action of 5-hydroxytryptamine on sympathetic preganglionic neurons. Exp Brain Res 3:299

11. Henderson VE, Roepke MH (1933) On the mechanisms of erection. Am J Physiol 106:441

12. Langley JN, Anderson HK (1895-1896) The innervation of the pelvic and adjoining viscera: III. The external generative organs. $\mathrm{J}$ Physiol 19:85

13. Lue TF (1986) The mechanism of penile erection in the monkey. Semin Urol 4:217

14. Lue TJ, Takamura T, Schmidt RA, Palubkinskas AJ, Tanagho EA (1983) Hemodynamics of erection in the monkey. J Urol 130:1237

15. Nadelhalft I, Groat WC de, Morgan C (1980) Location and morphology of parasympathetic preganglionic neurons in the sacral spinal cord of the cat revealed by retrograde axonal transport of horseradish peroxidase. J Comp Neurol 193:265

16. Semans JH, Langworthy OR (1938) Observation on the neurophysiology of sexual function in the male cat. J Urol 40:836

17. Siroky MB, Krane RJ (1983) Neurophysiology of erection. In: Krane RJ, Siroky MB, Goldstein I (eds) Male sexual dysfunction. Little Brown, Boston, pp 9-21

18. Sjöstrand NO, Klinge E (1979) Principal mechanisms controlling penile retraction and protrusion in rabbits. Acta Physiol Scand 106:199

19. Sjöstrand NO, Klinge E (1979) Changes in penile volume during some cardiovascular reflexes and reactions in rabbit. Acta Physiol Scand 106:327

20. Steers WD, McConnel J, Benson G (1984) Some pharmacologic effect of yohimbine on human and rabbit penis. J Urol 131:799

21. Steers WD, Mallory B, Groat WC de (1987) Electrophysiological analysis of penile reflexes in the rat. $J$ Urol 137:376A 